\title{
Micromechanical Analysis of Hybrid Composites Reinforced with Unidirectional Natural Fibres, Silica Microparticles and Maleic Anhydride
}

\author{
Leandro José da Silva ${ }^{\mathrm{a}}$, Túlio Hallak Panzera*, André Luis Christoforo ${ }^{\mathrm{a}}$, \\ Juan Carlos Campos Rubio ${ }^{\mathrm{b}}$, Fabrizio Scarpa ${ }^{\mathrm{c}}$ \\ ${ }^{a}$ Department of Mechanical Engineering, Federal University of São João Del Rei - UFSJ, \\ Brazil, Praça Frei Orlando, 170, São João Del Rei, MG, Brazil \\ ${ }^{\mathrm{b}}$ Department of Mechanical Engineering, Federal University of Minas Gerais - UFMG, \\ Belo Horizonte, $M G$, Brazil \\ 'Advanced Composites Centre for Innovation and Science, University of Bristol, Bristol, UK
}

Received: February 18, 2012; Revised: July 19, 2012

\begin{abstract}
The work describes the analytical and experimental characterisation of a class of polymeric composites made from epoxy matrix reinforced with unidirectional natural sisal and banana fibres with silica microparticles and maleic anhydride fabricated by manual moulding. The analytical models, ROM rule of mixtures and Halpin-Tsai approach, have been used in conjunction with a Design of Experiments (DOE) analysis from tensile tests carried out on 24 different composites architectures. The following experimental factors were analyzed in this work: type of fibres (sisal and banana fibres), volume fraction of fibres (30\% and 50\%) and modified matrix phase by adding silica microparticles (0\%wt, 20\%wt and 33\%wt) and maleic anhydride (0\%wt and 2\%wt). The ROM approach has shown a general good agreement with the experimental data for composites manufactured with $30 \% \mathrm{vol}$ of natural fibres, which can be attributed to the strong adhesion found between the phases. On the opposite, the semi empirical model proposed by Halpin and Tsai has shown greater fidelity with composites manufactured from $50 \%$ vol of natural fibres, which exhibit a weak interfacial bonding. The addition of microsilica and maleic anhydride in the system did not enhance the adhesion between the phases as expected.
\end{abstract}

Keywords: biocomposites, laminates, mechanical properties

\section{Introduction}

Biocomposites made from polymeric matrices and natural fibres appeared during the last decade as a sustainable alternative material for many applications related to aerospace, automotive and structural engineering. Interest towards an increased use of biocomposite structural materials has grown from the surging demand for low cost materials from environmental-friendly renewable sources, and the possibility of finding an alternative to traditional composites made of synthetic fibres ${ }^{1}$. The research and development activity on the use and disposal/recycling of synthetic fibres and resins derived from petroleum has also been motivated by increasingly stringent requirements by legal authorities, as well as by the high cost of the use of synthetic fibres for some non high-end engineering applications ${ }^{1}$.

A variety of natural fibres have been evaluated as reinforcement phase in polymeric composites, such as the bagasse from sugar cane, sisal, jute, curauá, flax, piassava and banana plant $^{2}$. Among them, the sisal fibre constitutes perhaps the most promising due to its low cost, high mechanical properties and market availability. Direct extraction of banana fibres is not common practice ${ }^{3}$, however

*e-mail: panzera@ufsj.edu.br this particular type of biofibre can be considered as a side waste product from the cultivation of banana plants. The fibres extracted from the pseudo-stem of banana plant exhibit interesting mechanical properties for polymeric composites reinforcements ${ }^{1}$.

One of the main difficulties when dealing with natural composites is the adhesion between fibres and matrices ${ }^{4,5}$, mainly due to the hydrophilic and hydrophobic characteristics showed by the fibres and the polymers, respectively. However, the chemical affinity between the cellulose and the polymeric matrix can be improved by the modification of the fibre surface ${ }^{6,7}$ or the polymer ${ }^{8-11}$, using chemical additives like maleic anhydride.

Mishra et al. ${ }^{6}$, Naik and Mishra ${ }^{7}$, evaluated the effect of adding maleic anhydride on the sisal and banana fibres surface adhesion, observing a significant reduction of the water absorption and an increase of the modulus of elasticity, hardness and impact strength. An alternative method to improve the mechanical performance of biocomposites is by adding a second reinforcement phase. In that sense, several studies involving the fabrication of hybrid composites of polymeric matrices reinforced with fibres and nano or microparticles of ceramic minerals have been reported in open literature ${ }^{12-17}$. During a biocomposite 
failure, the crack initiates in the matrix phase and increases the debonding between fibre and the matrix itself ${ }^{18}$. When the crack propagation reaches the ceramic particles along the fibre-matrix interface, the crack is impeded to penetrate through the locations where the particles are concentrated, because of the high strength provided by the ceramics. Hence, additional effort is required for the crack to propagate through the fibre-particle interface or the particle-matrix interfaces (whichever is longer). This additional effort not only reduces the crack propagation velocity, but also increases the mechanical strength of the composite. One of the major difficulties in developing hybrid composites reinforced with fibres and particles is the prediction of the effective mechanical and physical properties ${ }^{19}$. The problem is more accentuated for structural biocomposites, because their natural fibres exhibit large variations in properties, due to the uncertainties associated to the environmental conditions (moisture, soil, temperature) in which these natural materials are produced $^{20}$. The absence of robust micromechanical models predicting the mechanical properties of these hybrid biocomposites is a major obstacle towards the design of structural components using these novel types of composite ${ }^{19}$.

Several models have been used in open literature to predict the effective properties of composite materials reinforced with long and short fibres, such as Rule of mixture $(\mathrm{ROM})^{19,20}$, Halpin-Tsai ${ }^{20,21}$, shear-lag analysis ${ }^{20,22}$ and Hashin-Strickman ${ }^{23}$. The rule of mixture (ROM) has shown its effectiveness on predicting the tensile strength of different natural fibres reinforced HDPE (high-density polyethylene $)^{24}$. Halpin-Tsai model is also found to be the most effective equation in predicting the Young's modulus of composites containing different types of natural fibres ${ }^{21}$

The Rule of mixture (ROM) is the simplest available micromechanical analysis model that can be used to predict the elastic properties of a composite material ${ }^{19,20}$. As an application of the ROM approach, Equation 1 shows how to estimate the effective modulus of elasticity $\left(\mathrm{E}^{*}\right)$ of the composite, as a function of the properties of the fibres and matrix materials, considering the direction of fibre alignment. $\mathrm{E}_{\mathrm{F}}, \mathrm{E}_{\mathrm{M}}, \mathrm{V}_{\mathrm{F}}$ and $\mathrm{V}_{\mathrm{M}}$ are the modulus and volume fractions of the fibre and matrix materials respectively.

$$
\mathrm{E}^{*}=E_{f} V_{f}+E_{m} V_{m}
$$

The rule of mixture assumes a perfect bonded interface between matrix and reinforcement(s). This assumption may be unrealistic for the majority of real manufactured composites, and therefore it is useful to adopt semi-empirical models like the Halpin-Tsai one ${ }^{25}$, which compensates for non-perfect interface conditions. The calculation of the uniaxial tensile Young's modulus for a unidirectional composite according to Halpin-Tsai's approach is illustrated in Equation 2:

$$
E^{*}=\frac{E_{m}\left(1+\xi \eta V_{f}\right)}{1-\eta V_{f}}
$$

Where $\eta$ is given as:

$\eta=\frac{E_{f}-E_{m}}{E_{f}+\xi E_{m}}$

The parameter $\xi$ in Equations 2 and 3 is a shape fitting variable to fit the Halpin-Tsai equation to the experimental data, which describes also the packing arrangement and the geometry of the reinforcing fibres ${ }^{20}$ :

$$
\xi=\frac{E_{f}\left(E^{*}-E_{m}\right)-V_{f} E^{*}\left(E_{f}-E_{m}\right)}{E_{m}\left(E_{f}-E^{*}\right)-V_{m}\left(E_{f}-E_{m}\right)}
$$

In this work it was evaluated the mechanical behaviour of a polymeric composite reinforced with unidirectional natural fibres, such as sisal and banana fibres, by the use of micromechanical models and experimental tests. The maleic anhydride was also investigated as a coupling agent between the phases. The experimental Young's modulus was compared with the uniaxial one predicted by rule of mixture and Halpin-Tsai equations. From the micromechanical analyses presented, it is possible to observe the effect of the hybridization and chemical additive on the interfacial adhesion between the constitutive phases.

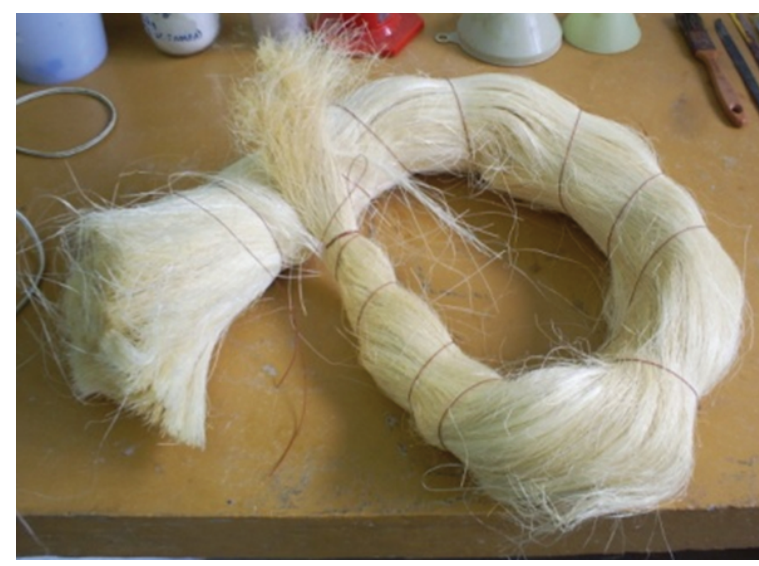

(a)

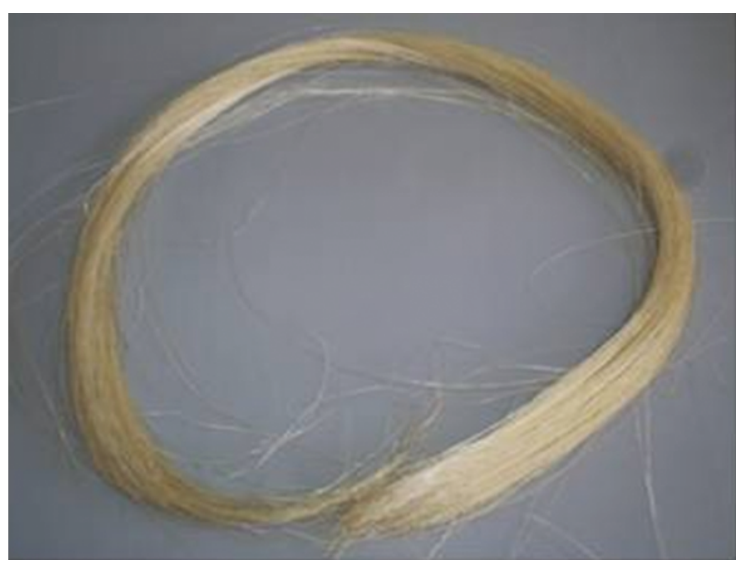

(b)

Figure 1. Sisal fibres (a) and banana fibres (b). 


\section{Material and Methods}

The polymeric composites were fabricated from modified and non-modified epoxy matrix, supplied by Resiqualy Company (São Paulo - Brazil), and from dispersive phase of unidirectional sisal (Figure 1a) and banana fibres (Figure 1b) supplied by Sisalsul Company (São Paulo - Brazil). The fibres were extracted, washed and combed by the supplier, with no chemical treatment. The matrix phase was modified by the addition of silica microparticles and maleic anhydride. The silica microparticles were supplied by Moinhos Gerais Company (Minas Gerais - Brazil), and classified by sieving process in monomodal range of 400-500 US-Tyler (0.037-0.025 mm). Table 1 exhibits the physical and mechanical properties of the silica powder were provided by Moinhos Gerais Company. The apparent density was determined using a gas pycnometer by Micromeritics model AccuPyc 1330 and the mechanical properties were estimated via dynamic ultra micro hardness tester by Shimadzu model DUH-211. The resin and the hardener were combined; afterwards the silica microparticles were added and hand-mixed by 5 minutes in room temperature around $22^{\circ} \mathrm{C}$.

Tensile tests were carried out according to ASTM D3822-07 ${ }^{[26]}$ and ASTM D638-03 ${ }^{[27]}$ standards to determine the tensile strength and modulus of elasticity of the fibres and matrix phase, respectively. The test speeds were set as $3 \mathrm{~mm} / \mathrm{min}$ for sisal and banana fibres and $2 \mathrm{~mm} / \mathrm{min}$ for polymeric matrices.

Figure 2 shows the samples for the non-modified and modified matrices which were used to evaluate the physical properties such as apparent density, apparent porosity and water absorption based on BS $10545-3^{[28]}$ standard. The samples were fabricated manually by hand-mixed of epoxy resin, silica particles and maleic anhydride, for 5 minutes in room temperature around $22^{\circ} \mathrm{C}$. As a part of the overall mechanical characterisation of the composites, the tensile

Table 1. Properties of silica particles supplied by Moinhos Gerais Company.

\begin{tabular}{lccc}
\hline \multicolumn{1}{c}{ Properties } & Unity & Lower limit & Higher limit \\
\hline Apparent density & $\mathrm{kg} / \mathrm{m}^{3}$ & 2170 & 2220 \\
Young's modulus & $\mathrm{GPa}$ & 56 & 74 \\
Tensile strength & $\mathrm{MPa}$ & 45 & 155 \\
Compressive strength & $\mathrm{MPa}$ & 1100 & 1600 \\
\hline
\end{tabular}

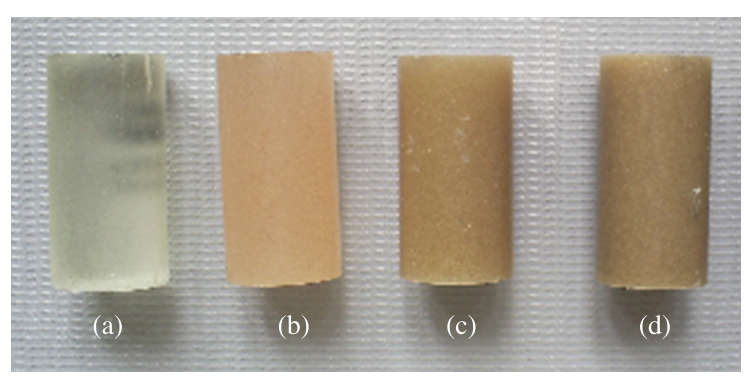

Figure 2. Non-modified matrix (a) and modified matrices by addition of $2 \%$ wt of maleic anhydride (b), $20 \%$ wt of silica microparticles (c) and 33\%wt of silica microparticles (d). strength of the pure epoxy matrices was also determined experimentally.

The Design of Experiment (DOE) activity was carried out considering as experimental factors the type of natural fibres (sisal and banana), volume fraction of fibres (30\% and 50\%), maleic anhydride (0\%wt and $2 \% \mathrm{wt}$ ) and silica microparticles (0\%wt, 20\%wt and 33\%wt). The combination of these factors leads to investigate a total of 24 experimental conditions (see Table 2).

Preliminary tests were conducted in order to set the upper volume fraction of fibres $(50 \%)$ and silica particles (33\%wt) in the system, to obtain a suitable surface finishing and lower porosity. A large percent of natural fibres contributes to an overall lower cost of the composite (i.e. for a 50/50\%vol laminate, the cost of epoxy resin corresponds nearly to ten times higher than the sisal phase) and also a more sustainable composite material in terms of recycling and sourcing. Mixture time (5 minutes), cure time (7 days), room temperature $\left(\sim 22^{\circ} \mathrm{C}\right)$ and the epoxy resin matrix were kept constants during the DOE process.

The biocomposite laminates were fabricated aligning manually the fibres by the aid of a metal frame. The manual moulding process was carried out over a glass plate covered by a cloth parting (Armalon), providing good surface finishing to the lamina. The polymeric matrix (modified and non-modified) was spread on the fibres by the use of spatula and roller aerator. A glass fibre composite was used to protect the specimen ends at the clamping area, avoiding premature crack during the tensile testing (see Figure 3).

A scanning electron microscope (SEM - Hitachi T-3000) was used to observe the cross section of the composites. The tensile and flexural testing was carried out following the BSI standard $2747^{[29]}$ using an Autograph machine monitored by a Topazium software with load cell maximum capacity of $20 \mathrm{kN}$. The test speed of the tensile tests was $2 \mathrm{~mm} / \mathrm{min}$.

A randomization procedure was adopted during the sample fabrication and experimental tests. This randomization let an arbitrary ordering of the experimental conditions, avoiding that non controlled factors affect the responses ${ }^{30}$.

The effective modulus of the composites was estimated using the ROM and Halpin-Tsai model. The particulate phase was not directly considered in the micromechanical analysis, using instead non-modified and modified matrices mechanical properties in the models. The comparison between experimental and predicted results allows verifying whether the particles and/or the chemical additions contribute to the fibre-matrix adhesion.

\section{Results}

Table 3 shows the physical and mechanical properties of sisal and banana fibres evaluated within this work ${ }^{31}$. Table 3 shows the mean values of the properties with the respective standard deviations. The banana fibres exhibited in general a lower density and higher porosity than sisal fibres. The tensile strength between the different types of fibres is quite similar; however the banana fibres appear stiffer than the sisal ones, showing a modulus of elasticity of $31.6 \mathrm{GPa} \pm 2.8$. The critical constituent responsible for natural fibre strength and stiffness are cellulose microfibrils. These microfibrils have a width ranging from 5 to $30 \mathrm{~nm}$, are highly crystalline materials 
Table 2. Experimental conditions.

\begin{tabular}{|c|c|c|c|c|}
\hline Conditions & Type of fibres & Volume fraction $(\%)$ & Maleic anhydride (\%wt) & Silica addition (\%wt) \\
\hline $\mathrm{C} 1$ & Sisal & 30 & 0 & 0 \\
\hline $\mathrm{C} 2$ & Sisal & 30 & 2 & 0 \\
\hline $\mathrm{C} 3$ & Sisal & 30 & 0 & 20 \\
\hline $\mathrm{C} 4$ & Sisal & 30 & 2 & 20 \\
\hline $\mathrm{C} 5$ & Sisal & 30 & 0 & 33 \\
\hline C6 & Sisal & 30 & 2 & 33 \\
\hline $\mathrm{C} 7$ & Sisal & 50 & 0 & 0 \\
\hline $\mathrm{C} 8$ & Sisal & 50 & 2 & 0 \\
\hline C9 & Sisal & 50 & 0 & 20 \\
\hline $\mathrm{C} 10$ & Sisal & 50 & 2 & 20 \\
\hline $\mathrm{C} 11$ & Sisal & 50 & 0 & 33 \\
\hline $\mathrm{C} 12$ & Sisal & 50 & 2 & 33 \\
\hline $\mathrm{C} 13$ & Banana & 30 & 0 & 0 \\
\hline $\mathrm{C} 14$ & Banana & 30 & 2 & 0 \\
\hline $\mathrm{C} 15$ & Banana & 30 & 0 & 20 \\
\hline $\mathrm{C} 16$ & Banana & 30 & 2 & 20 \\
\hline $\mathrm{C} 17$ & Banana & 30 & 0 & 33 \\
\hline $\mathrm{C} 18$ & Banana & 30 & 2 & 33 \\
\hline $\mathrm{C} 19$ & Banana & 50 & 0 & 0 \\
\hline $\mathrm{C} 20$ & Banana & 50 & 2 & 0 \\
\hline $\mathrm{C} 21$ & Banana & 50 & 0 & 20 \\
\hline $\mathrm{C} 22$ & Banana & 50 & 2 & 20 \\
\hline $\mathrm{C} 23$ & Banana & 50 & 0 & 33 \\
\hline $\mathrm{C} 24$ & Banana & 50 & 2 & 33 \\
\hline
\end{tabular}

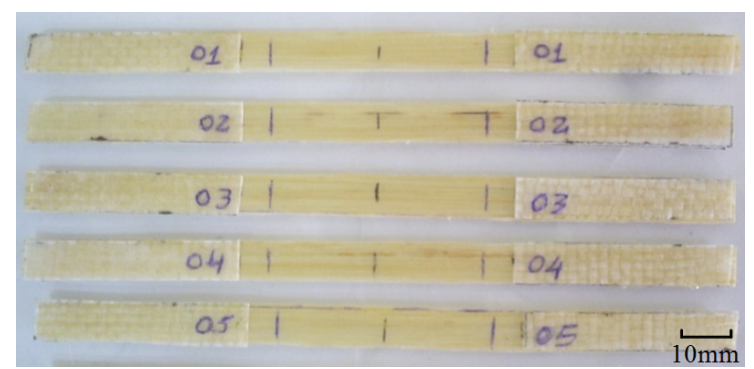

Figure 3. Tensile test specimens.

formed by the aggregation of long thread like bundles of molecules stabilized laterally by hydrogen bonds between hydroxyl groups and oxygens of adjacent molecules ${ }^{32}$. According to Joseph et al..$^{33}$ the percent of cellulose in sisal and banana fibres is nearly 70 and $83 \%$, respectively.

Figure 4 shows the stress-strain behaviour of the sisal and banana fibres under tensile loading. The stress-strain curve of the sisal (Figure 4a) and banana (Figure 4b) fibres can be approximately divided in four stages. During stage (i), the stiffness reaches a maximum of $200 \mathrm{MPa}$, increasing to a value of $450 \mathrm{MPa}$ during stage (ii). The $450 \mathrm{MPa}$ value was used to calculate the Young's modulus to be inserted in the Equations 1-4 for micromechanics analysis. Stage (iii) features a large elongation of the fibres, which can be attributed to the initial fraying effect. During stage (iv) one can observe a significant increase in tensile
Table 3. Properties of sisal and banana fibres (mean values and standard deviation).

\begin{tabular}{lcc}
\hline \multicolumn{1}{c}{ Properties } & Sisal fibre & Banana fibre \\
\hline Diameter $(\mu \mathrm{m})$ & $192.5( \pm 26.3)$ & $131.1( \pm 17.7)$ \\
Apparent density $\left(\mathrm{g} / \mathrm{cm}^{3}\right)$ & $1.41( \pm 0.12)$ & $1.35( \pm 0.09)$ \\
Apparent porosity $(\%)$ & $76.21( \pm 2.01)$ & $86.69( \pm 1.76)$ \\
Tensile strength $(\mathrm{MPa})$ & $887( \pm 143)$ & $1063( \pm 259.5)$ \\
Modulus of elasticity $(\mathrm{GPa})$ & $16.4( \pm 2.5)$ & $31.56( \pm 2.8)$ \\
\hline
\end{tabular}

stress, achieving a maximum value close to $1000 \mathrm{MPa}$ for sisal fibres and $1200 \mathrm{MPa}$ for banana ones.

Table 4 shows the physical and mechanical properties related to the modified and non-modified termoset matrices. Table 4 shows the mean values of the properties with the respective standard deviations. It is apparent that, although, the addition of maleic anhydride did not affect the physical properties of the matrices, the addition of silica microparticles increased the material's density, which can be attributted to the higher density of the silica particles $\left(\sim 2.2 \mathrm{~g} . \mathrm{cm}^{-3}\right)$. However, the inclusion of silica in the composites did not affect the apparent porosity and water absorption of the matrices.

Figure 5 shows the mechanical behaviour of the modified matrices for $0 \% \mathrm{wt}$ and $2 \% \mathrm{wt}$ of maleic anhydride dispersions, revealing an increase of the tensile strength and tenacity when the chemical agent is added. However, the chemical additive did not affect significantly the value of the modulus of elasticity. From Figure 5 it is possible to observe that adding silica 


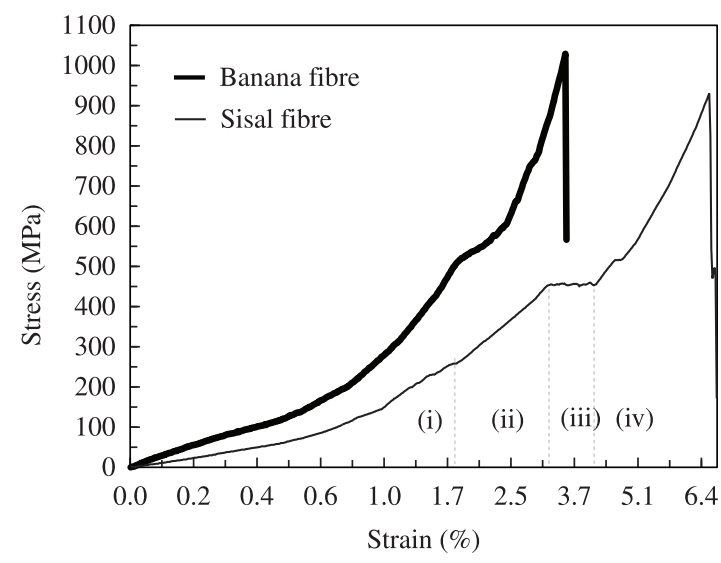

Figure 4. Tipical stress/strain curves for sisal and banana fibres.

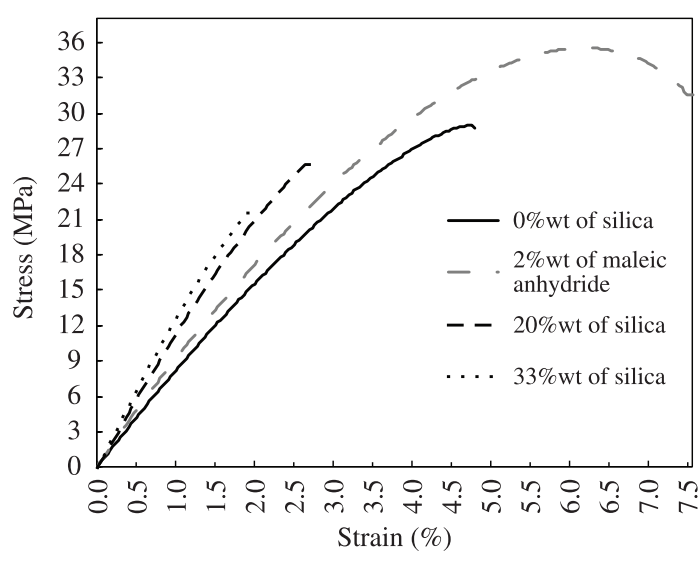

Figure 5. Stress/strain curves of the non-modified and modified matrices with maleic anhydride and silica microparticles.

Table 4. Properties of polymeric matrices (mean values and standard deviation).

\begin{tabular}{lccccc}
\hline \multicolumn{1}{c}{ Setup } & $\begin{array}{c}\text { Apparent density } \\
\left(\mathbf{g} / \mathbf{c m}^{\mathbf{3}}\right)\end{array}$ & $\begin{array}{c}\text { Apparent porosity } \\
(\boldsymbol{\%})\end{array}$ & $\begin{array}{c}\text { Water absorption } \\
(\boldsymbol{\%})\end{array}$ & $\begin{array}{c}\text { Tensile strength } \\
(\mathbf{M P a})\end{array}$ & $\begin{array}{c}\text { Modulus of elasticity } \\
(\mathbf{G P a})\end{array}$ \\
\hline Epoxy resin & $1.16( \pm 0.00)$ & $0.30( \pm 0.07)$ & $0.26( \pm 0.06)$ & $31.99( \pm 2.72)$ & $0.83( \pm 0.05)$ \\
$2 \%$ of MA & $1.15( \pm 0.00)$ & $0.30( \pm 0.06)$ & $0.26( \pm 0.06)$ & $35.73( \pm 0.87)$ & $0.81( \pm 0.03)$ \\
$20 \%$ of silica & $1.28( \pm 0.01)$ & $0.30( \pm 0.06)$ & $0.24( \pm 0.05)$ & $26.26( \pm 1.36)$ & $0.95( \pm 0.03)$ \\
$33 \%$ of silica & $1.34( \pm 0.02)$ & $0.29( \pm 0.07)$ & $0.22( \pm 0.05)$ & $22.54( \pm 2.64)$ & $1.10( \pm 0.07)$ \\
\hline
\end{tabular}

Table 5. Results obtained from tensile testing and micromechanical analysis.

\begin{tabular}{|c|c|c|c|c|c|}
\hline $\begin{array}{l}\text { Experimental } \\
\text { conditions }\end{array}$ & $\begin{array}{l}\text { Experimental modulus } \\
\text { of elasticity (MPa) }\end{array}$ & $\begin{array}{l}\text { Rule of mixture } \\
\text { (MPa) }\end{array}$ & $\mathbf{E} / \mathbf{N}^{*}$ & $\begin{array}{l}\text { Halpin-Tsai } \\
\text { (MPa) }\end{array}$ & $\mathrm{E} / \mathrm{N}^{* *}$ \\
\hline $\mathrm{C} 1$ & 5722 & 5502 & 1.04 & 2400 & 2.38 \\
\hline $\mathrm{C} 2$ & 5559 & 5487 & 1.01 & 2376 & 2.34 \\
\hline $\mathrm{C} 3$ & 5632 & 5583 & 1.01 & 2526 & 2.23 \\
\hline $\mathrm{C} 4$ & 6158 & 5423 & 1.14 & 2275 & 2.71 \\
\hline C5 & 5440 & 5690 & 0.96 & 2693 & 2.02 \\
\hline C6 & 5217 & 5766 & 0.90 & 2811 & 1.86 \\
\hline $\mathrm{C} 7$ & 5912 & 8616 & 0.69 & 4923 & 1.20 \\
\hline C8 & 5030 & 8605 & 0.58 & 4902 & 1.03 \\
\hline C9 & 4978 & 8673 & 0.57 & 5035 & 0.99 \\
\hline $\mathrm{C} 10$ & 5298 & 8559 & 0.62 & 4813 & 1.10 \\
\hline C11 & 4866 & 8750 & 0.56 & 5183 & 0.94 \\
\hline $\mathrm{C} 12$ & 4762 & 8804 & 0.54 & 5287 & 0.90 \\
\hline C13 & 9105 & 10050 & 0.91 & 3770 & 2.42 \\
\hline C14 & 8650 & 10035 & 0.86 & 3745 & 2.31 \\
\hline $\mathrm{C} 15$ & 8045 & 10131 & 0.79 & 3897 & 2.06 \\
\hline C16 & 7685 & 9971 & 0.77 & 3644 & 2.11 \\
\hline $\mathrm{C} 17$ & 7270 & 10238 & 0.71 & 4066 & 1.79 \\
\hline $\mathrm{C} 18$ & 7850 & 10314 & 0.76 & 4185 & 1.88 \\
\hline C19 & 8255 & 16196 & 0.51 & 8721 & 0.95 \\
\hline $\mathrm{C} 20$ & 7920 & 16185 & 0.49 & 8699 & 0.91 \\
\hline $\mathrm{C} 21$ & 6450 & 16253 & 0.40 & 8834 & 0.73 \\
\hline $\mathrm{C} 22$ & 6940 & 16139 & 0.43 & 8609 & 0.81 \\
\hline $\mathrm{C} 23$ & 7260 & 16330 & 0.44 & 8984 & 0.81 \\
\hline C24 & 6565 & 16384 & 0.40 & 9089 & 0.72 \\
\hline
\end{tabular}

*Relation between experimental and predicted modulus of elasticity by rule of mixture model. **Relation between experimental and predicted modulus of elasticity by Halpin-Tsai equations. 
microparticles leads to a decrease of the tensile strength of the matrices. As expected the Young's modulus of the epoxies increased by $14 \%$ and $32 \%$ when $20 \%$ wt and $33 \%$ wt of silica were added, respectively. This behaviour can be attributed to the high stiffness of the particulate phase, contributing to increase the modulus of elasticity of the matrices. These results are in accordance with previous works published in the open literature ${ }^{13-14}$, where the Young's modulus of the composites increases by the addition of particles into polymeric matrix.

Table 5 contains the results related to the experimental (E) and numerical (N) unidirectional Young's modulus of the fibres. The analytical values from the micromechanical models, were calculated based on the individual mean

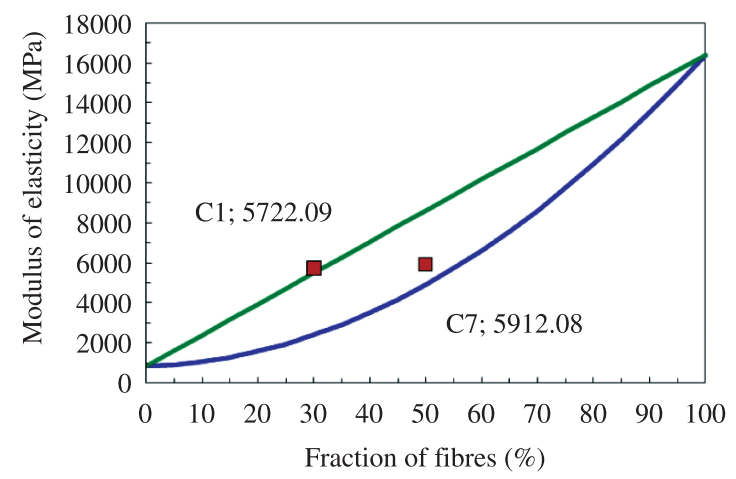

(a)

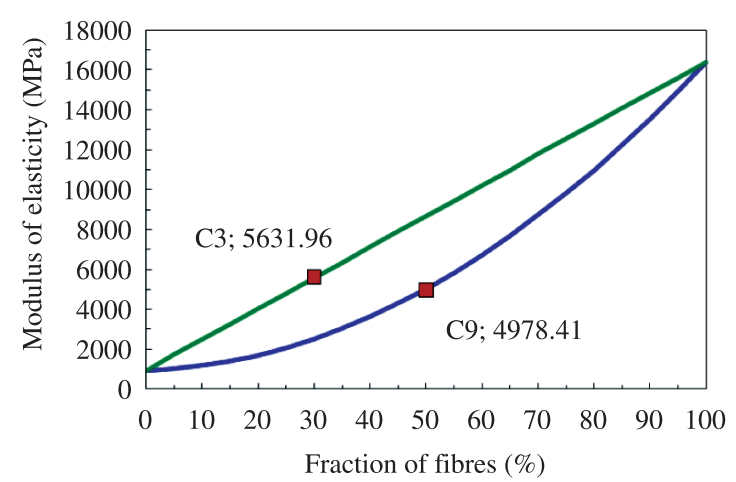

(c)

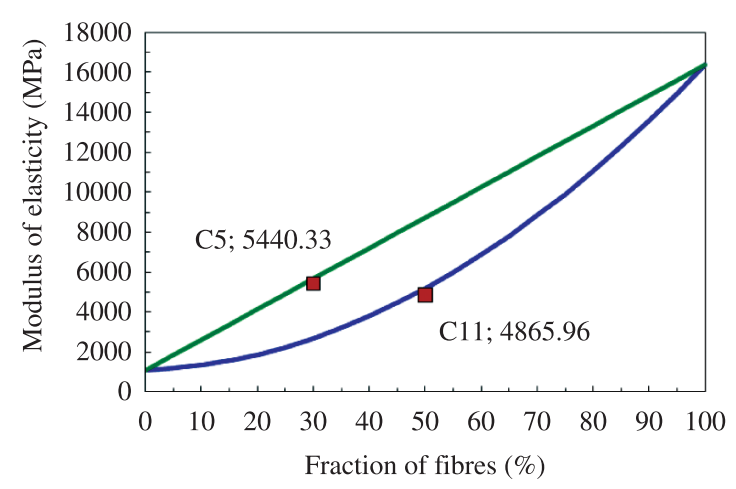

(e) properties of the fibres and matrix phases from Tables 3 and 4 . Table 5 shows the relation between the experimental (E) and numerical $(\mathrm{N})$ modulus of elasticity. If the value $\mathrm{E} / \mathrm{N}$ is higher than 1.0 , indicates that the experimental value is higher than the predicted one.

\subsection{Composites fabricated with sisal fibres}

Figure 6 shows the comparison between ROM, Halpin-Tsai and experimental results for the $\mathrm{C} 1$ to $\mathrm{C} 12$ sisal fibres composites.

Figure 6 a shows the modulus of elasticity for the $\mathrm{C} 1$ and $\mathrm{C} 7$ composites; i.e. those composites manufactured with $30 \%$ vol and $50 \%$ vol of sisal fibres, respectively,

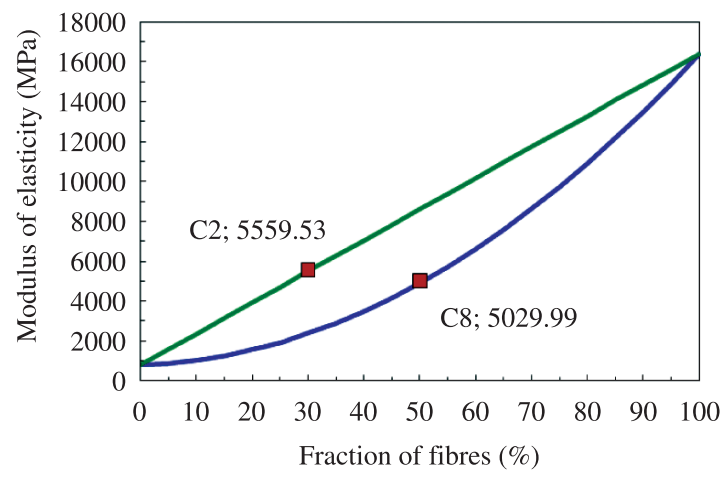

(b)

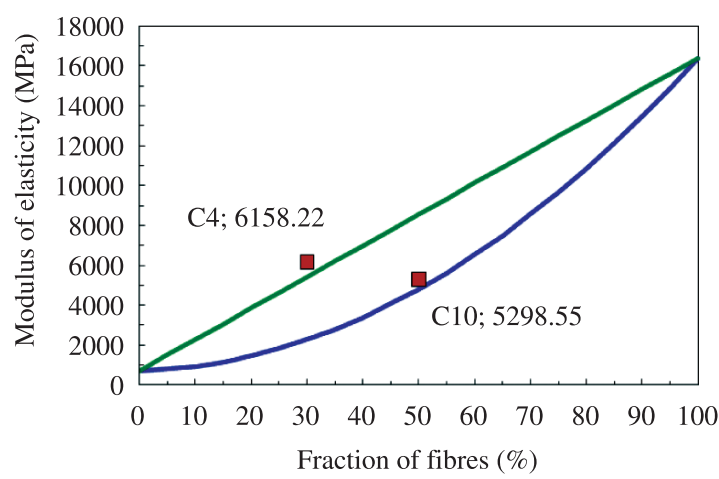

(d)

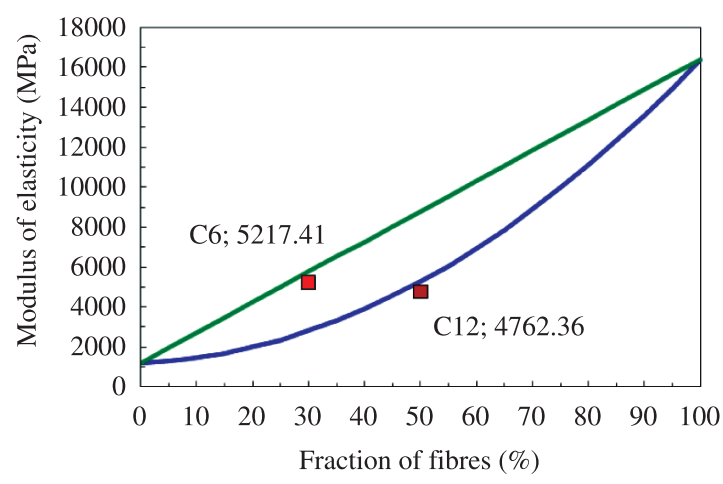

(f)

Rule of mixture 
with no silica and maleic anhydride addition. It can be observed that the composite with $30 \%$ vol of fibres follows the ROM model $\left(\mathrm{E} / \mathrm{N}^{*}=1.04\right)$, while the Halpin-Tsai approach underestimates the effective modulus of elasticity $\left(\mathrm{E} / \mathrm{N}^{* *}=2.38\right)$. This result indicates a strong interfacial adhesion for $\mathrm{C} 1$ composite.

On the opposite, the experimental results for $\mathrm{C} 7$ composite showed higher agreement with the Halpin-Tsai equation (see Table 5), which suggests the presence of an non-perfect bonding condition at the interface between fibres and matrix. This behaviour can be attributed to the small amount of matrix phase in the system (50\%), which

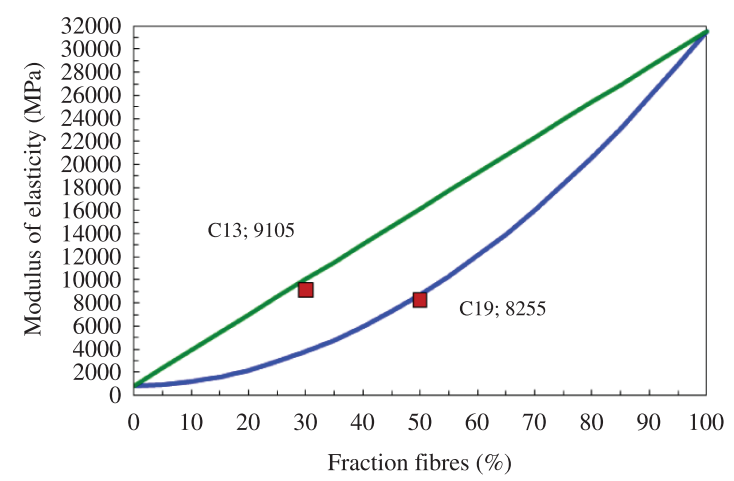

(a)

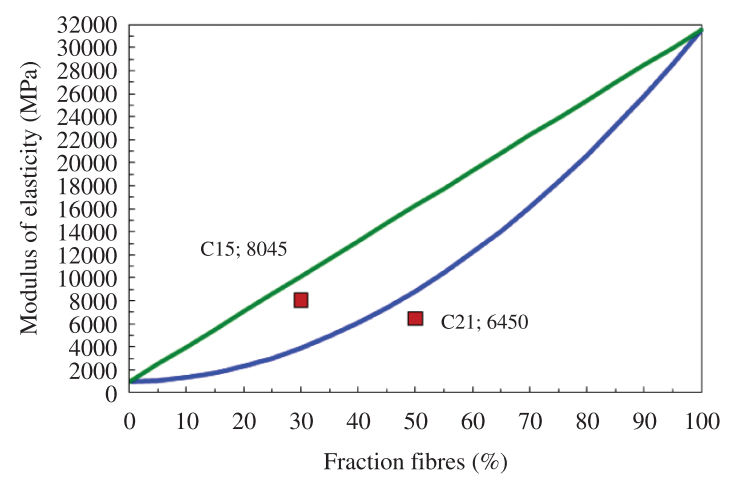

(c)

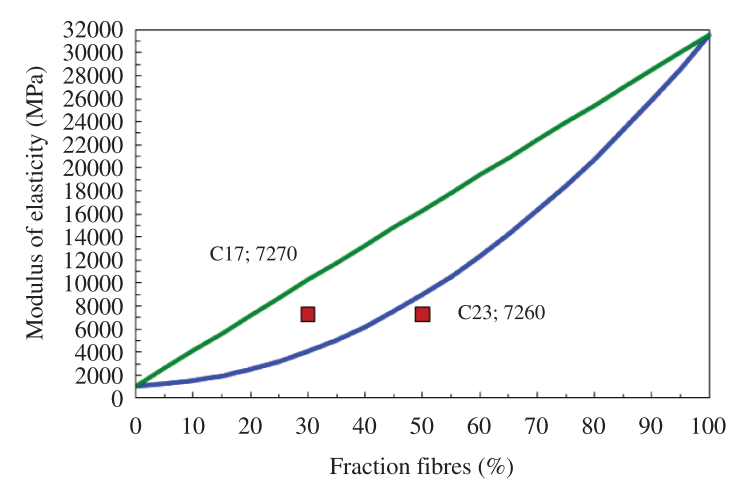

(e) affects the matrix wetting capacity around the fibres, and consequently, the increase in porosity of the composites.

Figure $6 \mathrm{~b}$ features the Young's modulus of the composites fabricated with maleic anydride addition, corresponding to $\mathrm{C} 2$ and $\mathrm{C} 8$ composites (30\%vol and $50 \%$ vol of sisal fibres, respectively). Similarly to the composites with non-modified epoxy resin shown in Figure $6 \mathrm{a}$, the interface condition can be considered perfect for the low level of sisal fibres (30\%vol), exhibiting a E/N* ratio of 1.01 . The improved agreement provided by the Halpin-Tsai approach $\left(\mathrm{E} / \mathrm{N}^{* *}=1.06\right)$ suggests also in this case the existence of an imperfect interfacial condition was

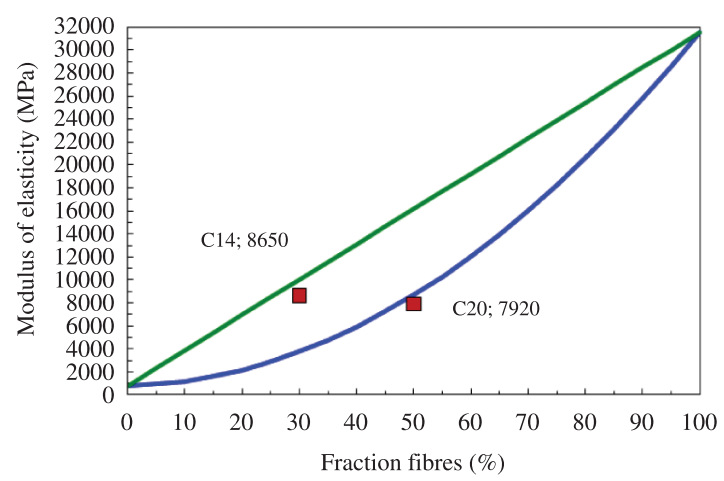

(b)

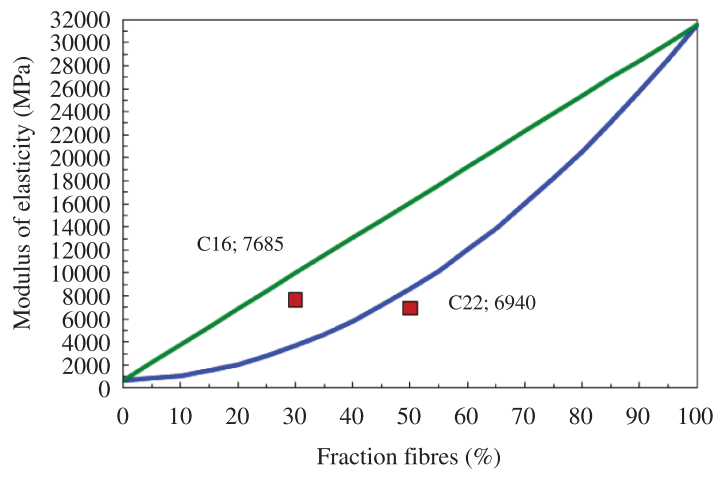

(d)

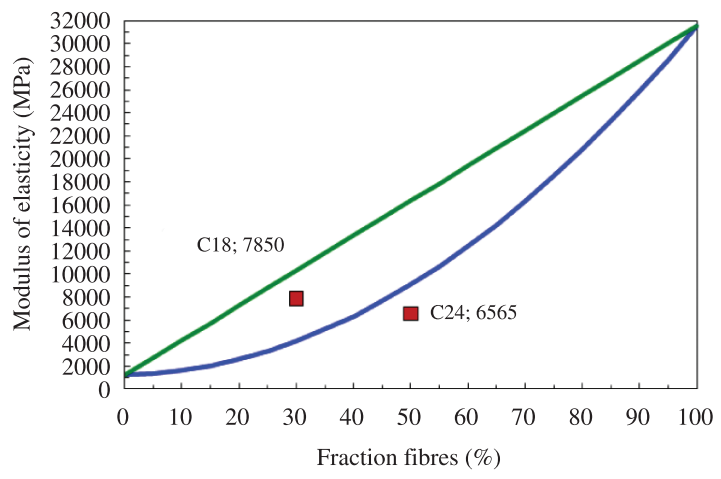

(f) Rule of mixture 
achieved for the composites with high level of sisal fibres addition (50\%vol).

The micromechanical analyses of the composites made with $20 \%$ wt of microsilica addition (C3 and C9 composites) is shown in Figure 6c. It can be observed a particularly good agreement $\left(\mathrm{E} / \mathrm{N}^{*}=1.01\right)$ between the experimental and rule of mixture modulus predicted for the composite manufactured with $30 \%$ vol of sisal fibres (C3 composite). On the opposite, the composite with high level of sisal fibres $(50 \% \mathrm{vol})$ revealed an imperfect interface condition, exhibiting a large deviation of rule of mixture prediction $\left(\mathrm{E} / \mathrm{N}^{*}=0.57\right)$; while the Halpin-Tsai model provided a higher fidelity prediction $\left(\mathrm{E} / \mathrm{N}^{* *}=0.99\right)$. Figure $6 \mathrm{~d}$ shows the estimated modulus for the composites made with $20 \%$ wt of silica and $2 \%$ wt of maleic anhydride addition ( $\mathrm{C} 4$ and $\mathrm{C} 10$ composites). The results indicate that the maleic anhydride affected the rheology of the system, increasing the elastic modulus of the composites. The increase of the fibre fraction reduced the interfacial adhesion between the phases, a fact also confirmed by the low fidelity of the ROM prediction in this case $\left(\mathrm{E} / \mathrm{N}^{*}=0.62\right)$. Figure $6 \mathrm{e}$ presents the behaviour of the $\mathrm{C} 5$ and $\mathrm{C} 11$ composites, i.e. those composites manufactured with $30 \%$ vol and $50 \%$ vol of sisal fibres and $33 \%$ wt of silica addition. The composites made with $30 \%$ vol of fibres featured a higher agreement between the rule of mixture model and experimental Young's modulus $\left(\mathrm{E} / \mathrm{N}^{*}=0.96\right)$. However, the composite with $50 \%$ of fibres was better described by the Halpin-Tsai approach $\left(\mathrm{E} / \mathrm{N}^{* *}=0.94\right)$.

Although the addition of $33 \%$ wt of silica microparticles increased the stiffness of the matrix (see Table 4), it was not able to increase the modulus of elasticity of the composites. This behaviour can be attributed to the increase of surface area due to the silica particles addition, affecting not only the rheology of the system but also the matrix wetting capacity on the fibre surface. The addition of silica microparticles also increases the porosity of the composites, therefore contributing to the reduction of the mechanical properties.

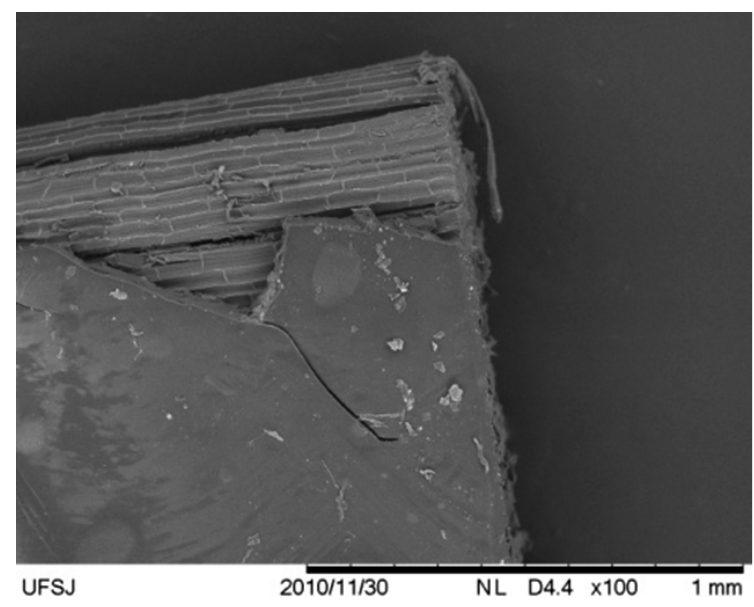

(a)
Divergence between the experimental results and predicted stiffness by ROM and Halpin-Tsai models is shown in Figure 6f for the C6 and C12 composites, which were manufactured with $30 \% \mathrm{vol}$ and $50 \% \mathrm{vol}$ of sisal fibres, respectively, and $33 \% \mathrm{wt}$ of silica microparticles and $2 \% \mathrm{wt}$ of maleic anhydride added into the polymeric matrix phase. The modulus of elasticity of the matrix was increased by silica and maleic anhydride addition (Figure 5). However, the stiffer matrices did not originate stiffer composites. This behaviour confirms the hypothesis of fibre-matrix interface adhesion reduction provided by the addition of high content of silica micro particles.

\subsection{Composites manufactured with banana fibres}

Figure 7 shows the analytical predicted and experimental results related to the composites reinforced with banana fibres (C13 to $\mathrm{C} 24$, see Table 2). The same discussions performed for the composites reinforced with sisal fibres (see section 3.1) can be extended for the composites reinforced with banana fibres.

The composites manufactured with low level of banana fibres $(30 \%$ vol) showed a better agreement with the rule of mixture model, while the composites with high level of fibres ( $50 \%$ vol) were better described using the Halpin-Tsai approach, indicating therefore a poor interface condition for those composites compared to the ones of the previous case. However, based on the results shown in Table 5, it is possible to verify that the elastic moduli of banana fibre composites are in general lower than the elastic moduli estimated by the micromechanical analysis. Higher divergence between experimental moduli and predicted moduli were observed for the banana fibre composites in comparison to sisal fibre composites, for both micromechanical models. This result implies that the composites fabricated with sisal fibres show in general a sounder fibre-matrix adhesion than the banana fibre composites.

Figure 8 shows the backscatter mode SEM images at $100 \times$ of magnification featuring the failure surface of the

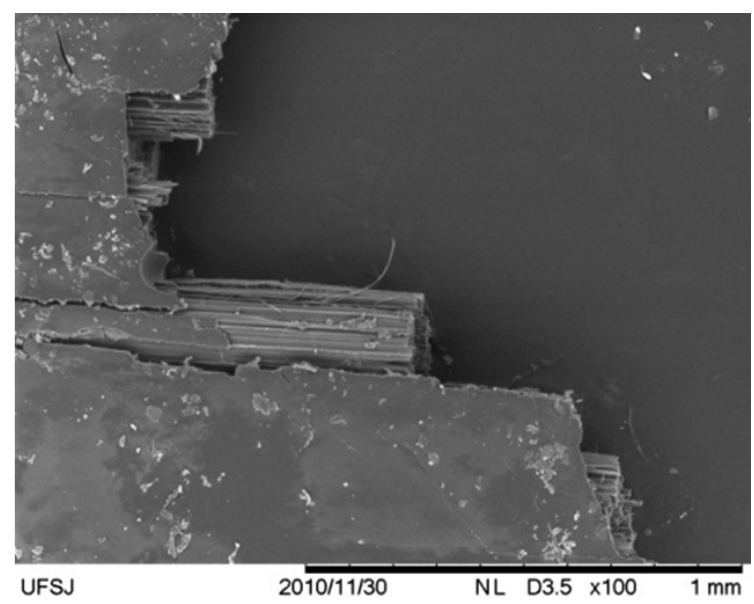

(b)

Figure 8. Backscatter electron imaging (BSE) at 100x of magnification for rupture surface of composites manufatured with sisal fibres (a) and banana fibres (b). 
sisal (Figure 8a) and banana (Figure 8b) fibre composites after tensile testing. The sisal fibre composites shows a fracture mode more brittle than the banana fibre composites.

Based on the investigations of Facca et al. ${ }^{20}$ and $\mathrm{Ku}$ et $\mathrm{al}^{24}{ }^{24}$ the Halpin-Tsai model well described the experimental modulus of HDPE (High-density polyethylene) composites reinforced with different types of short natural fibres and volume fractions varying from $0 \%$ wt up to $40 \%$ wt. In contrast, the rule of mixture was not able to predict the experimental data. In the present work, the composites were fabricated with unidirectional banana fibres. The Young's modulus was better predicted by Halpin-Tsai model when $50 \%$ vol of fibres were added. However, when the composites were fabricated with $30 \%$ vol of natural fibres, the rule of mixture presented a better prediction, especially for the sisal fibres. This result reveals the Rule of mixture (ROM) can be acceptably applied to estimate the tensile modulus of biocomposites with good interfacial adhesion.

\section{Conclusions}

The experimental and analytical Young's moduli of structural biocomposites based on sisal and banana fibres were evaluated in this work. The experimental results were generated through a Design of Experiments approach. The main conclusions from this work are the following:

- The banana fibres have shown a general higher stiffness than sisal fibres, however the sisal fibres exhibited a superior tensile strength than the banana ones;

- The mechanical behaviour under tensile loading is very similar for both natural fibres, featuring four different stages in their stress-strain behaviour. A fraying effect of fibres was observed when the stress is around $450 \mathrm{MPa}$, subsequently the stiffness is increased, achieving a maximum tensile stress close to $1000 \mathrm{MPa}$ for sisal fibres and $1200 \mathrm{MPa}$ for banana fibres;

- The addition of $2 \%$ wt of maleic anhydride into matrix phase provided not only the increase of tensile strength, but also the tenacity of the polymer itself;

\section{References}

1. Silva RV. Compósito de resina poliuretana derivada de óleo de mamona e fibras vegetais. [Tese]. São Carlos: Escola de Engenharia de São Carlos, Universidade de São Paulo; 2003.

2. Bledzki AK, Mamun AA and Faruk O. Abaca fiber reinforced PP composites and comparison with jute and flax PP composite. Express Polymer Letters. 2007; 1:755-762. http://dx.doi. org/10.3144/expresspolymlett.2007.104

3. Mukhopadhyay S, Fangueiro R and Shivankar V. Variability of Tensile Properties of Fibers from Pseudostem of Banana Plant. Textile Research Journal. 2009; 79:387-393. http://dx.doi. org/10.1177/0040517508090479

4. Maldas D and Kokta BV. Influence of polar monomers on the performance of wood fiber reinforced polystyrene composites. I. Evaluation of critical conditions. International Journal of Polymeric Materials. 1990; 14:165-189. http://dx.doi. org/10.1080/00914039008031512

5. Lyons JS and Ahmed MR. Factors Affecting the Bond Between Polymer Composites and Wood. Journal of Reinforced
- The addition of silica microparticles into the matrix phase led not only to the reduction of tensile strength, but also to the increase of the Young's modulus of the polymer;

- The micromechanical analysis provided some indications about the interfacial conditions between fibres and matrices within the natural composites. The rule of mixture showed higher fidelity when low levels of fibres $(30 \% \mathrm{vol})$ enhancing the wetting capacity of the matrix were added. The Halpin-Tsai results were providing a higher correlation with those composites fabricated with $50 \%$ vol of fibres, revealing the presence of a poor interfacial adhesion;

- The sisal fibres are less porous than banana fibres, therefore absorbing less matrix phase. Low porosity indicates better interfacial condition, and higher fidelity of the predictions provided by both ROM and Halpin-Tsai models;

- The addition of silica microparticles increases the stiffness of the matrices, but does not seem sufficient to improve the elastic moduli of the composites, with a decrease of the level of adhesion between the composites phases;

- The addition of maleic anhydride did not show a relevant effect on the interfacial adhesion, featuring instead a small increase of the Young's modulus for the composites C4 and C8 (sisal fibres - 20\%wt of silica addition) and $\mathrm{C} 18$ and $\mathrm{C} 24$ (banana fibres $-33 \% \mathrm{wt}$ of silica addition). Further investigation need to be performed to assess the effect of this material as an efficient coupling agent.

\section{Acknowledgements}

The authors would like to thank the financial support of CAPES and the material suppliers: Resiqualy Company (epoxy resin), Sisalsul Company (sisal fibres) and Moinhos Gerais Company (silica particles).

Plastics and Composites. 2005; 24:404-405. http://dx.doi. org/10.1177/0731684405044898

6. Mishra S, Naik JB and Patil YP. The compatibilising effect of maleic anhydride on swelling and mechanical properties of plant-fiber-reinforced novolac composites. Composites Science and Technology. 2000; 60:1729-1735. http://dx.doi. org/10.1016/S0266-3538(00)00056-7

7. Naik JB and Mishra S. Esterification Effect of Maleic Anhydride on Swelling Properties of Natural Fiber/High Density Polyethylene Composites. Journal of Applied Polymer Science. 2007; 106:2571-2574. http://dx.doi.org/10.1002/app.25329

8. López Manchado MA, Arroyo M, Biagiotti J and Kenny JM. Enhancement of mechanical properties and interfacial adhesion of PP/EPDM/Flax fiber composites using maleic anhydride as a compatibilizer. Journal of Applied Polymer Science. 2003; 90:2170-2178. http://dx.doi.org/10.1002/ app. 12866

9. Sombatsompop N, Yotinwattanakumtorn C and Thongpin C. Influence of type and concentration of maleic anhydride 
grafted polypropylene and impact modifiers on mechanical properties of PP/Wood sawdust composites. Journal of Applied Polymer Science. 2005; 97:475-484. http://dx.doi.org/10.1002/ app. 21765

10. Kim S, Moon J, Kim G and Ha S. Mechanical properties of polypropylene/natural fiber composites: Comparison of wood fiber and cotton fiber. Polymer Testing. 2008; 27:801-806. http://dx.doi.org/10.1016/j.polymertesting.2008.06.002

11. Soleimani M, Tabil L, Panigrahi S and Opoku A. The effect of fiber pretreatment and compatibilizer on mechanical and physical properties of flax fiber-polypropylene composites. Journal of Polymers and the Environment. 2008; 16:74-82. http://dx.doi.org/10.1007/s10924-008-0102-y

12. Rosso P, Ye L, Friedrich K and Sprenger S. A Toughened Epoxy Resin by Silica Nanoparticle Reinforcement. Journal of Applied Polymer Science. 2006; 100:1849-1855. http://dx.doi. org/10.1002/app.22805

13. Isik I, Yilmazer U and Bayram G. Impact modified epoxy/montmorillonite nanocomposites: synthesis and characterization. Polymer. 2003; 44:6371-6377. http://dx.doi. org/10.1016/S0032-3861(03)00634-7

14. Yasmin A, Abot JL and Daniel IM. Processing of clay/epoxy nanocomposites by shear mixing. Scripta Materialia. 2003; 49:81-86. http://dx.doi.org/10.1016/S13596462(03)00173-8

15. Haque A, Shamsuzzoha M, Hussain F and Dean D. S2Glass/Epoxy Polymer Nanocomposites: Manufacturing, Structures, Thermal and Mechanical Properties. Journal of Composite Materials. 2003; 20:1821-1837. http://dx.doi. org/10.1177/002199803035186

16. Subramaniyan AK and Sun CT. Enhancing compressive strength of unidirectional polymeric composites using nanoclay. Composites Part A: Applied Science and Manufacturing. 2006; 37:2257-2268. http://dx.doi. org/10.1016/j.compositesa.2005.12.027

17. Tsai JL and Cheng YL. Investigating Silica Nanoparticle Effect on Dynamic and Quasi-static Compressive Strengths of Glass Fiber/Epoxy Nanocomposites. Journal of Composite Materials. 2009; 43:3143-3155. http://dx.doi. org/10.1177/0021998309345317

18. Cao Y and Cameron J. Impact properties of silica particle modified glass fiber reinforced epoxy composite. Journal of Reinforced Plastics and Composites. 2006; 25:761-769. http:// dx.doi.org/10.1177/0731684406063536

19. Casaril A, Gomes ER, Soares MR, Fredel MC and Al-Qureshi HA. Análise micromecânica dos compósitos com fibras curtas e partículas. Matéria. 2007; 12:408-419.

20. FaccaAG, KortschotMT andYan N.Predicting the elastic modulus of natural fibre reinforced thermoplastics. Composites Part A Applied Science and Manufacturing. 2006; 37:1660-1671. http://dx.doi.org/10.1016/j.compositesa.2005.10.006
21. Biagiotti J, Fiori S, Torre L, López-Manchado MA and Kenny JM. Mechanical Properties of Polypropylene Matrix Composites Reinforced With Natural Fibers: A Statistical Approach. Polymer Composites. 2004; 25:26-36. http://dx.doi. org/10.1002/pc.20002

22. Nairn JA. On the Use of Shear-Lag Methods for Analysis of Stress Transfer in Unidirectional Composites. Mechanics of Materials. 1997; 26:63-80. http://dx.doi.org/10.1016/S01676636(97)00023-9

23. Sejnoha M and Zeman J. On adequacy of the Hashin-Shtrikman variational principles applied to polymer matrix based random fibrous composites. In: Proceedings of the VIII International Conference on Computational Plasticity - COMPLAS VIII; 2005; Barcelona. Barcelona; 2005.

24. $\mathrm{Ku} \mathrm{H}$, Wang $\mathrm{H}$, Pattarachaiyakoop $\mathrm{N}$ and Trada $\mathrm{M}$. A review on the tensile properties of natural fiber reinforced polymer composites. Composites Part B: Engineering. 2011; 42:856-873. http://dx.doi.org/10.1016/j.compositesb.2011.01.010

25. Halpin JC and Kardos JL. The Halpin-Tsai Equations: A Review. Polymer Engineering \& Science. 1976; 16:344-352. http://dx.doi.org/10.1002/pen.760160512

26. American Society for Testing and Materials - ASTM. ASTM D 3822: Standard Test Method for Tensile Properties of Single Textile Fibers. ASTM; 2007.

27. American Society for Testing and Materials - ASTM. ASTM D 638: Standard Test Method for Tensile Properties of Plastics. ASTM; 2003

28. British Standard. BS 10545-3: Ceramic Tiles - Part 3: Determination of water absorption, apparent porosity, apparent relative density and bulk density. BS; 1997.

29. British Standard. BS 2747: Glass fibre reinforced plastics, tensile test. BS; 1998

30. Werkema MCC and Aguiar S. Planejamento e análise de experimentos: como identificar e avaliar as principais variáveis influentes em um processo. Belo Horizonte: Fundação Christiano Ottoni, Escola de Engenharia da UFMG; 1996.

31. Silva LJ. Estudo Experimental e Numérico das propriedades mecânicas de compósitos poliméricos laminados com fibras vegetais. [Dissertação]. São João Del Rei: Universidade Federal de São João Del Rei; 2011. 151 p.

32. Deepa B,AbrahamE, Cherian BM, BismarckA. Blaker JJ, Pothan LA et al. Structure, morphology and thermal characteristics of banana nano fibers obtained by steam explosion. Bioresource Technology. 2011; 102:1988-1997. PMid:20926289. http:// dx.doi.org/10.1016/j.biortech.2010.09.030

33. Joseph K, Tolêdo Filho RD, James B, Thomas S and Carvalho LH. A Review on Sisal Fiber Reinforced Polymer Composites. Revista Brasileira de Engenharia Agrícola e Ambiental. 1999; 3:367-379. 